\title{
A mãe desbundada: uma tradução baiana para o monólogo La Mamma Fricchettona de Dario Fo e Franca Rame ${ }^{1}$

\author{
A mãe desbundada: A Bahian translation \\ for the monologue La Mamma Fricchettona \\ by Dario Fo and Franca Rame
}

Alessandra Paola Caramori ${ }^{2}$

Cristiana Almeida de Sousa ${ }^{3}$ 


\section{Resumo}

Este artigo apresenta uma breve discussão sobre tradução a partir da análise do monólogo $A$ mãe desbundada que é uma tradução de La mamma fricchettona escrito pelo casal italiano Dario Fo e Franca Rame. Reconhecendo os dois textos como fenômenos culturais distintos, algumas escolhas do tradutor Sérgio Nunes Melo serão destacadas e comentadas, utilizando como pressuposto teórico os conceitos de domesticação e estrangeirização apresentados por Lawrence Venuti (2002). Também, dialogando com as ideias de Rosemary Arrojo (2007) se discute a produção de significados que se dá num processo de tradução.

Palavras-chave: Dario Fo; Franca Rame; escolhas do tradutor; domesticação; Estrangeirização
Abstract

This article presents a brief discussion about translation from the analysis of the monologue entitled $A$ mãe desbunda$d a$. This monologue is a translation of $L a$ mamma fricchettona, written by the Italian couple Dario Fo and Franca Rame. In order to recognise both texts as distinct cultural phenomena, some choices of the translator Sérgio Nunes Melo will be highlighted and commented, using the theoretical presupposition of domestication and foreignization concepts presented by Lawrence Venuti (2002). Also, in the light of Rosemary Arrojo ideas (2007), it will be discussed the production of meanings that occurs in a translation process.

Keywords: Dario Fo; Franca Rame; translator's choices; domestication; foreignization

E-ISSN: 2358.6958

\footnotetext{
1 Este artigo é parte de uma pesquisa realizada no Instituto de Letras da Universidade Federal da Bahia (UFBA). (Sousa, 2015)

2 Profa. Dra. Associada de língua e literatura italianas - Universidade Federal da Bahia (UFBA) - alecaramori@gmail.com

3 Mestre em Literatura e Cultura pela Universidade Federal da Bahia (UFBA) - cristianacult@gmail.com
} 


\section{O tradutor e seu objetivo tradutório}

Uma tradução em que a língua estrangeira continue aparecendo é uma tradução inacabada. Com essa afirmação o tradutor Sérgio Nunes Melo evidencia que num processo tradutório ele busca apagar as marcas da cultura de partida presentes no texto estrangeiro e insere elementos da cultura local. Sendo assim, é a partir da análise do monólogo A mãe desbundada uma tradução do monólogo La mamma fricchettona escrito pelo casal italiano Dario Fo e Franca Rame que será possível identificar e discutir essas outras marcas apresentadas pelo tradutor. Primeiramente, faz-se necessária uma breve apresentação a fim de compreender melhor seu objetivo e suas escolhas.

Sérgio Nunes Melo é homem das letras e do teatro. Professor e coordenador do Curso de Artes Cênicas da Universidade Federal de Santa Catarina - UFSC. Possui Bacharelado em Letras pela Universidade Estadual do Rio de Janeiro - UERJ e Mestrado em Literaturas de Língua Inglesa pela mesma universidade. Doutor em Artes da Cena pela University of Toronto. Formado pela Scuola d' Arte Drammatica Paolo Grassi (célula originária do Piccolo Teatro di Milano). Membro do GERICO, Grupo de Estudos sobre o riso e o cômico. Também exerce os papéis de ator, roteirista, autor teatral, dramaturgo e diretor.

Como prática tradutória merece destaque a tradução do texto Assim é (se lhe parece), de Pirandello, publicado pela Editora Alaúde em 2011 e encenado por Marco Antônio Pâmio, em São Paulo, 2014. Também traduziu Esta noite se improvisa e 0 Homem da flor na boca, ambos de Pirandello.

Para entender seu objetivo tradutório, vale destacar que, à época da tradução do monólogo La mamma fricchettona, em 2012, Nunes estava ministrando um curso de comédia no Bacharelado de Teatro - Habilitação em Interpretação na Universidade Federal da Bahia - UFBA e precisava de um texto instigante. De modo que o próprio tradutor explicita: "Eu precisava acreditar que o texto suscitasse o riso. Também queria que não fosse um texto conhecido demais. La mamma fricchettona nunca tinha sido encenado na Bahia" (Nunes Melo, apud Souza, 2015, p.77)4. A tradução analisada teve como objetivo final a sua encenação, que ocorreu em cerca de quinze apresentações: algumas na Universidade Federal da Bahia e outras em espaços culturais da cidade de Salvador, como o Centro Cultural do Garcia, o Palacete das Artes, o vão do Teatro Castro Alves e o Passeio Público.

Traduzir um texto exige do tradutor uma interpretação cuidadosa e tomada de decisões. Uma prática tradutória sempre se inicia a partir de um texto-fonte que se coloca no mundo com suas particularidades culturais. $O$ ato de escrita acontece quando o tradutor realiza o processo de leitura e interpretação e acrescenta ao texto traduzido marcas culturais diferentes do que o texto-fonte traz.

Graciliano Ramos compara o trabalho do escritor ao de uma lavadeira para destacar o quanto o ato de escrever exige muito empenho e dedicação. Assim também é a tarefa do tradutor.

4 O texto de Dario Fo e Franca Rame já havia sido traduzido por Roberto Vignati e Michele Piccoli em 1984 para o espetáculo "Brincando em cima daquilo", protagonizado por Marília Pêra. 


\begin{abstract}
Deve-se escrever da mesma maneira com que as lavadeiras lá de Alagoas fazem em seu ofício. Elas começam com uma primeira lavada, molham a roupa suja na beira da lagoa ou do riacho, torcem o pano, molham-no novamente, voltam a torcer. Colocam o anil, ensaboam e torcem uma, duas vezes. Depois enxaguam, dão mais uma molhada, agora jogando água com a mão. Batem o pano na laje ou na pedra limpa, e dão mais uma torcida e mais outra, torcem até não pingar do pano uma só gota. Somente depois de feito tudo isso é que elas dependuram a roupa lavada na corda ou no varal, para secar. Pois quem se mete a escrever devia fazer a mesma coisa. A palavra não foi feita para enfeitar, brilhar como ouro falso; a palavra foi feita para dizer. (Ramos, 2006, contracapa)
\end{abstract}

Não é demais dizer que Sérgio Nunes Melo tem consciência dessa difícil labuta e assumiu o desafio de traduzir um monólogo que trata das questões referentes às submissões sociais e sexuais da mulher e, ao mesmo tempo, apresenta várias conotações intertextuais e alusões a uma realidade política italiana das décadas de 60 e 70 do século passado.

\title{
Dario Fo e Franca Rame também fizeram um teatro que discutiu sobre questões da mulher
}

Não se pode falar da história recente da Itália dos últimos sessenta anos sem se referir a Dario Fo e Franca Rame. Eles não pararam enquanto viveram. Escreveram, produziram e encenaram inúmeros espetáculos. Participaram de forma ativa das questões políticas, sociais e civis da Itália e do mundo.

Dario e Franca formavam um casal na vida e na arte. Mas eles possuíam as suas individualidades e suas origens familiares eram diversas e isso contribuiu para engrandecer e enaltecer o humano que há em cada artista.

Rame nasce em Parabiago, uma província de Milão, em 18 de julho de 1929, filha de Domenico Rame e da professora Emilia Baldini. Seu avô Pio foi um dos últimos e maiores marionetistas italianos. A família Rame possuía um teatro itinerante todo em madeira, que podia ser montado e desmontado em diferentes praças, e, juntamente, com os outros filhos, Enrico, Lina, Pia e o tio Tommaso, alguns primos, alguns atores e atrizes contratados, constituíam a famosa companhia / Rame que percorria pequenas cidades das regiões da Lombardia e de Piemonte, recitando dramas históricos, comédias e óperas modernas. É importante dizer que, até 1940, eles conseguiram manter as tradições teatrais mais antigas. Portanto, Franca cresceu nesse ambiente teatral que the permitiu aprender a arte da improvisação.

Dario Fo nasce em 1926 numa cidadezinha da província de Varese, próximo ao lago Maggiore, San Giano. Diferentemente de Franca, Dario não vem de uma família de atores profissionais. Seu pai, Felice, era chefe da estação ferroviária local. Sua mãe, Pina Rota, de origem camponesa, era muito criativa e talentosa. A sua família era formada por mais dois irmãos, Fulvio e Bianca, e o seu avô materno, Bristìn, que era agricultor e vendia suas próprias verduras. Esse avô, morava em Lomellina, que também pertencia à Lombardia. Ele percorria toda a região vendendo seus produtos e, na intenção de atrair clientes, contava as mais diversas fábulas grotescas nas quais conseguia inserir episódios reais acontecidos nas cidades por onde passava. Foi com 
seu Bristìn que o pequeno Dario passava suas férias e foi ele seu primeiro modelo: o do fabulador satírico grotesco.

É interessante evidenciar que a região do lago Maggiore, na qual estava inserido Dario Fo, conservava toda uma cultura e uma tradição popular muito desenvolvida, viva e integrada à realidade do dia-a-dia, como afirma Veneziano (2002, p. 79). Exibiam-se aí os fabulatori, pessoas que recontavam histórias a partir de modelos seiscentistas, quinhentistas e, até, medievais. No entanto, esses contadores de histórias fantásticas não tinham consciência de que eram filhos da tradição giullaresca. Veneziano (2002, p. 111) destaca:

Mais tarde, Fo estudará e pesquisará, à exaustão, a figura do giullare, seus monólogos, seus textos, suas músicas, sua irreverência, traduzindo-o em sua obra-prima: Mistero Buffo. Dessa figura e dessa tradição, sugou a seiva para os seus procedimentos de cena.

Não é demais observar que Fo foi influenciado pela tradição itinerante e popular, a qual se tornou, assim, um dos elementos de base de sua formação teatral. Também, a atriz Franca Rame exerceu um papel fundamental na formação do marido e, nas palavras de Veneziano (2002, p. 114), "[...] ensinou-lhe a arte do improviso e a fórmula da comédia ottocentesca".

Se entre 1954 e 1968 Fo e Rame tornaram-se muito famosos em toda a Europa, participando de vários espetáculos, cinema e televisão, vale pontuar que as suas apresentações já eram marcadas pela crítica satírica. Mas, o casal percebeu que era preciso mudar, pois se viam como "jograis da burguesia", que ajudavam os ricos a rir de suas próprias ganâncias e injustiças, facilitando-os a digerir melhor a realidade na qual estavam inseridos. Eles queriam se tornar "jograis do proletariado". De modo que o ano de 1968 foi um momento de muitas rupturas. Veneziano (2002) relata que Dario e Franca deixaram a comodidade e o prestígio dos teatros do centro e saíram à procura de um público que talvez nunca tivesse visto teatro, nem entrado numa elegante sala teatral. Portanto, é a partir desse período que Fo-Rame realiza um teatro cada vez mais engajado e voltado para as questões sociais e políticas da Itália e do mundo.

De modo que fazendo parte dessa fase de engajamento político e social, em 1977, Franca Rame estreava Tutta casa, letto e chiesa, em Milão, espetáculo sobre a condição da mulher e suas servidões sociais, sexuais, no dizer da própria Franca:

Este texto foi e é a toda hora representado em muitíssimos países. A condição da mulher, seja com avanços ou retrocessos, infelizmente é ainda semelhante em qualquer lugar. Quantas apresentações eu fiz? Mais de três mil.

O protagonista absoluto deste espetáculo sobre a mulher é o homem. Melhor dizendo, seu sexo! Não está presente $<<$ em carne e osso $>>$, mas está sempre aqui, entre nós, grande, enorme, que ameaça... nos esmaga!

Nós mulheres, há anos que lutamos pela nossa libertação, pedimos igualdade de direitos com o homem, igualdades sociais. Imagina! [...]. Pedimos igualdade social e igualdade de sexo. (Fo; Rame, 2005, p. 5, prólogo)

5 Questo testo è stato ed è tuttora rappresentato in moltissimi paesi. La condizione della donna, un po' più avanti, un po' più indietro, purtroppo è ancora simile ovunque. Quante repliche ho fatto? Più di tremila.

II protagonista assoluto di questo spettacolo sulla donna è l'uomo. Meglio, il suo sesso! Non è presente $<<$ in carne ed ossa >, ma è sempre qui, tra noi, grande, 
O Tutta casa, letto e chiesa é composto de seis monólogos que falam da condição da mulher de forma grotesca, cômica e dramática: Una donna sola, Il risveglio, La mamma fricchettona, Abbiamo tutte la stessa storia, Contrasto per una sola voce e Medea. Nesse espetáculo, Franca Rame está sozinha, sobre o palco da Palazzina Liberty, e vence a sua batalha pelo seu reconhecimento pessoal, se encontra e renasce.

Tanto trabalho, tanta adaptação a cada personagem, ao fim, tinha danificado o meu espírito. No sentido que eu me dizia... não serei mais capaz de interpretar, não sei... Quando fiz Tutta casa, letto e chiesa poderia ter encerrado no dia seguinte da primeira apresentação, pela satisfação que experimentei porque disse a mim mesma 'tudo bem, eu consigo, eu ainda consigo!'. O espetáculo foi um sucesso estrondoso [...]. Por isso criou-se uma grande celeuma nos jornais, na Itália e no exterior. Mas naquela noite, na Palazzina Liberty, apesar da neve, do frio e do teatro não lotado disse a mim mesma ' $\mathrm{Ok}$ estamos aqui... o espetáculo... ainda consigo... posso segurar um espetáculo sozinha! (D’Arcangelli, 2009, p. 200) ${ }^{6}$

É importante evidenciar que é a primeira vez que Franca aparece como coautora dos textos. Durante muito tempo a crítica italiana a considerou como um "complemento" do teatro político de Dario Fo. No entanto, Luciana D'Arcangeli, no livro I personaggi femminili nel teatro di Dario Fo e Franca Rame (2009), coloca Franca no centro da discussão, destacando a sua importância e o seu trabalho na produção dos textos e dos espetáculos.

O monólogo La mamma fricchettona apresenta a história de uma mulher casada, mãe de um jovem "extremista de esquerda", que resolve mudar de vida, para isso deixa o marido e o filho. Ela leva uma vida difícil como toda mulher que precisa conciliar o trabalho fora de casa; ser responsável, em grande parte, pela educação dos filhos e, ainda, fazer as atividades domésticas: "Eu também trabalhava oito horas, como ele. Só que tinha uma diferença substancial: quando nós voltávamos pra casa, eu continuava trabalhando outras oitenta horas. O meu marido ia assistir televisão e ficava esperando a janta" (Nunes Melo, apud Souza, 2015, p.63-64)

Há uma mulher que se anulou profissional e socialmente por amor e zelo extremos ao filho, enfim, à família. Ao ponto de deixar de perceber e fazer coisas simples da vida: "Quero falar, rir, cantar... Quero ficar olhando pro céu... Meu filho, você sabe que o céu é azul, e que eu não sabia mais disso?" (idem, p. p. 66).

Se Sérgio Nunes escolheu o texto La mamma fricchettona para ser traduzido para o português em razão da sua comicidade e para ser encenado, vale dizer que a escolha de analisar o monólogo A mãe desbundada aconteceu, essencialmente, por tratar sobre questões da mulher. Dario Fo e Franca Rame fizeram um teatro que tratou das questões políticas e sociais da Itália e do mundo. De modo que o tema sobre

enorme, che incombe... e ci schiaccia!"

Noi donne, sono anni che ci battiamo per la nostra liberazione, chiediamo parità di diritti con l'uomo, parità sociali. E quando mai! [...] Chiediamo parità sociale e parità di sesso. (Fo; Rame, 2005, p. 5) prólogo) (Tradução nossa).

6 Tutto questo lavorare, tutto questo adattarmi ad ogni personaggio mi aveva alla fine proprio lesionato lo spirito. Nel senso che mi dicevo... non sarò più capace di recitare, non so... Quando ho fato Tutta casa letto e chiesa avrei potuto chiudere il giorno dopo la prima dal piacere, perché mi sono detta "va bene! ce la faccio... ce la faccio ancora!". Lo spettacolo ebbe un successo strepitoso [...] Quindi fece un grosso scalpore sui giornali, sia in Italia che all'estero. Ma quella sera, in Palazzina Liberty, nonostante la neve, il freddo e il teatro non esaurito mi dissi "OK ci siamo... lo spettacolo... vado ancora bene... posso reggere uno spettacolo da sola! (Rame, 2005 apud D'Arcangeli, 2009, p. 200) (Tradução nossa) 
as mulheres, suas servidões, submissões e violências, sempre foi uma preocupação do casal que, ao longo do tempo, foi criando personagens femininas mais bem estruturadas e protagonistas de suas ações. Ainda hoje, quatro décadas depois, os textos de Dario e Franca nos servem para discutir e analisar a realidade da mulher.

\section{Marcas da cultura local nas escolhas do tradutor}

Os textos La mamma fricchettona e $A$ mãe desbundada devem ser reconhecidos como fenômenos culturais distintos. Paulo Henriques Britto afirma que com a "virada cultural" dos estudos de tradução: "os tradutólogos passaram a enfatizar que um texto só pode ser compreendido, e, portanto, traduzido, quando visto como um fenômeno cultural, dentro de um contexto rico e complexo, que vai muito além dos aspectos estritamente linguísticos" (Britto, 2012, p. 20). Logo é impossível não reconhecer as distintas identidades culturais do texto-fonte e do texto-alvo.

Venuti, em seu livro Escândalos da tradução: por uma ética da diferença (2002), traz um capítulo intitulado $A$ formação de identidades culturais, no qual expõe:

Meu objetivo é levar em consideração o modo como a tradução forma identidades culturais específicas e as mantém com um relativo grau de coerência e homogeneidade, mas também o modo como ela cria possibilidades para a resistência cultural, a inovação e a mudança em qualquer que seja o momento histórico. (Venuti, 2002, p.131-132)

Para Venuti, a tradução é obrigada a voltar-se para as diferenças culturais e linguísticas de um texto estrangeiro, podendo, com a mesma eficácia, promover ou reprimir a heterogeneidade na cultura doméstica. De modo que ele enfatiza a importância e a necessidade de os tradutores manterem as marcas de estrangeirização do texto-fonte no texto-alvo, a fim de aproximar o leitor da cultura estrangeira, evidenciar a diferença intercultural e se tornarem visíveis. A este processo dá-se o nome de estrangeirização.

Diferentemente da estrangeirização, a domesticação busca apagar as marcas da cultura-fonte, tornando o texto traduzido fluido e sem estranhamentos, fazendo parecer que se trata do texto original e não de uma tradução. Venuti não concorda com a domesticação total de um texto-alvo, mas reconhece que numa tradução a domesticação, também, é necessária.

Assim, a identidade cultural de cada texto está além da própria língua, seja esta o italiano ou o português. Para Britto "pois um idioma faz parte de um todo maior, que é o que denominamos de cultura; e as "coisas" reconhecidas por uma cultura não são as mesmas que as outras reconhecem. As diferenças podem se dar das maneiras mais diversas" (Britto, 2012, p.14). Vale dizer que para este artigo somente as marcas de domesticação realizadas pelo tradutor foram destacadas.

Os trechos seguintes são exemplos do empenho e da criatividade do tradutor em apropriar-se do sentido das expressões do texto-fonte e adaptá-las para a cultura-alvo. $O$ tradutor poderia ter deixado algumas marcas de estrangeirização do texto-fonte para que o leitor percebesse que se trata de uma tradução e poderia explicar essas diferentes marcas culturais com o uso de notas de rodapé. Uma escolha desta 
poderia interferir na fluidez da leitura do texto; em contrapartida, o leitor teria acesso à cultura-fonte. No entanto, o que há nos trechos que se seguem é uma busca do tradutor por adaptar as expressões para a cultura-alvo, totalmente de acordo com a sua ideologia, (já que, como afirma Sérgio Nunes, uma tradução que deixa transparecer a cultura de origem é uma tradução inacabada).

Analisando o título dos dois textos percebe-se que para caracterizar a personagem, os autores fazem uso de uma adjetivação que possui sentido e representatividade em suas respectivas culturas. Os termos "fricchettona" e "desbundada" apresentam correspondência entre si.

"Fricchettona" é a pessoa que possui um comportamento/uma atitude inconformista e/ou extravagante diante da realidade do mundo. Já "Desbunde" é uma gíria inventada no Brasil na década de 60 do século XX, e se referia àquele que abandonava a luta armada. Esta palavra foi evoluindo e passou a designar não somente as pessoas que tinham abandonado a resistência aos militares que governavam a Nação à época, mas, também, toda pessoa interessada em contracultura a ponto de viver seus ideais. E a personagem "mãe desbundada" apresenta as marcas desta contracultura. O tradutor escolheu um termo que representa bem toda uma conjuntura, uma realidade. "[...] O senhor vai entender: eu era uma mãe. Símbolo da repressão! Daí, eu disse pra mim mesma: se não falam pra mim porque sou mãe, eu pego esse pessoal: vou me disfarçar. De quê? De riponga, de despirocada, de desbundada, padre. O que são os desbundados, padre? São pessoas que fumam unzinho; roubam uma coisinha aqui, outra ali; não trabalham e estão sempre bem, enfim...".

Arrojo (2007) explica que a tradução, como a leitura, deixa de ser, portanto, uma atividade que protege os significados "originais" de um autor, e assume sua condição de produtora de significados; mesmo porque protegê-los seria impossível. Assim, constata-se que o tradutor a partir da cultura-alvo constrói novos significados para sua tradução. De modo que, no texto-fonte, temos a expressão "d'insaccato Molteni", para compreendê-la dentro da sua realidade cultural italiana, reconhece que "insaccato" é um tipo de salame preparado com carne triturada e ensacada e Agostino Molteni Salumi, utilizando antigas técnicas e somente "carne italiana", é responsável pela produção de ensacados frescos com carnes da espécie suína, há mais de 40 anos na Itália. No entanto, Sérgio Nunes, na sua atividade de produtor de significados, escolhe a palavra "sacolé" para substituir tal significado. Vale dizer que "sacolé" é o picolé vendido dentro de saco de plástico. Também na gíria, quer dizer saco plástico com pequena quantidade de droga.

Em "Pronto... ehhum volevo dire... padre, padre!", o tradutor apresenta a seguinte tradução: "Painho! Quer dizer... pa-padre!". Neste caso, temos um outro exemplo de domesticação. O uso de "Painho" por "padre" explicita as influências da cultura-alvo nas escolhas do tradutor. Ele mesmo afirma: "Lembro-me de ter colocado uma ou outra interjeição baiana na minha tradução exatamente porque estava em Salvador, fazendo teatro para a população local. Se fosse aqui em Floripa, eu tiraria, com toda a certeza, as marcas baianas" (Nunes Melo, apud Sousa, 2015, p. 78).

No trecho seguinte, novamente, o tradutor apropria-se das expressões do texto-fonte e consegue utilizar outras expressões que na cultura-alvo têm, também, uma 
carga de significação similar ao texto-fonte. As expressões "porcaccia d'una miseriaccia, 'sti caramba dell'ostrega...", pertecem a um linguajar vulgar, funcionam como um queixume da situação na qual a personagem fricchettona se encontra. Por meio do acréscimo do sufixo "ccia", temos em "porcaccia" e "miseriaccia" um aumento do valor já pejorativo das expressões "porca" e "miseria". "Ostrega" é uma interjeição com valor vivaz e cômico. A redução de "questi" para "sti" contruibui para o sentido informal da mensagem. O vocábulo "paquete", segundo o dicionário da língua portuguesa ${ }^{7}$, surgiu em 1810, quando os navios (paquetes) chegavam mensalmente, no mesmo dia, depois o sentido se expandiu para a menstruação das mulheres. $E$ "pentelho" refere-se aos pêlos pubianos. O tradutor utiliza "pentelho encravado em dia de paquete!" que, também, possui um sentido pouco polido, de lamento.

Nos próximos trechos, seguem outros exemplos de domesticação de expressões. O tradutor substituiu as marcas culturais do texto-fonte: "fabbricata a Monza" (cidade italiana industrial); un foulard greco dell'UPAIM, detto anche UPIM" ("Unico Prezzo Italiano Milano" - grande rede de lojas de departamento), por marcas da cultura-alvo, "made in Paraguay" e "um lenço grego da Riachuelo", apagando, assim, qualquer estranhamento na leitura e compreensão do texto-alvo.

O mesmo processo se dá em "padre zingaro calabrese" por "pai cigano do Capão". Em italiano zíngaro significa cigano e a região da Calabria a que o texto faz referência, em sua formação histórica foi constituída por ciganos. O tradutor utilizou "pai cigano do Capão", fazendo referência ao Capão, uma pequena cidade localizada no município de Palmeiras, a $445 \mathrm{~km}$ de Salvador, situada no Vale do Capão, que compõe a Chapada Diamantina.

O trecho seguinte domesticado é sobre gravidez $x$ trabalho. Lembrando que o texto de Fo-Rame refere-se ao planejamento familiar como se fosse um programa de desenvolvimento econômico "[...] anzi, l'ho voluto io 'sto figlio... preventivato: piano quinquennale!" e o texto de Nunes apresenta a condição da mulher trabalhadora brasileira "Eu queria o meu filho. Eu pensava na licença maternidade, nas férias sublimes que eu teria amamentando o meu bebê..." (Nunes Melo apud Souza, 2015, p 64).

É importante dizer que em A mãe desbundada de Sérgio Nunes, embora apresente as marcas culturais próprias da realidade da sociedade e da época em que a obra foi traduzida, a estória se mantém, a "mãe desbundada" vive as mesmas dificuldades e opressões da "mamma fricchettona", inserida numa realidade social que oprime a mulher, seus desejos e sua identidade.

Portanto, é preciso destacar que o tradutor diante do texto-fonte realizou escolhas de acordo com seu escopo tradutório, apagando as marcas da cultura estrangeira, tornando a leitura fluida como se não tratasse de uma tradução.

Por fim, essa breve análise possibilitou reconhecer quão complexa e difícil é a prática tradutória, permitindo percorrer de certa forma o caminho das pedras feito pelo tradutor, pois este, diante de um texto a ser traduzido, é jogado num ambiente que lhe exige fazer escolhas, muitas vezes difíceis e até indesejáveis, como bem explicita Britto:

7 Dicionário da língua portuguesa. Lisboa: Priberam Informática. Disponível em:<http://www .priberam.pt/DLPO>. Acesso: 10 jun. 2019. 
É preciso afirmar o caráter não trivial do trabalho de tradução, elucidar a verdadeira natureza da atividade, enfatizar as dificuldades e o que há de criativo e intelectualmente instigante nessa profissão, e negar os velhos chavões preconceituosos. (Britto, 2012, p. 18)

Sendo que os próprios versos do tradutor descrevem essa dificuldade, quando afirma que traduzir é "Pegar um peixe de rio/ doar-lhe o sal da saliva/ lançá-lo vivo no mar." De modo que no texto traduzido estão presentes algumas marcas culturais e autorais do tradutor que devolve um outro texto para o mundo.

\section{Referências}

ARROJO, Rosemary. Oficina de tradução: a teoria na prática. São Paulo: Ática, 2007.

BRITTO, Paulo Henriques. A tradução literária. Rio de Janeiro: Civilização Brasileira, 2012.

D'ARCANGELLI, Luciana. I personaggi femminili nel teatro di Dario Fo e Franca Rame. Firenze: Franco Cesati Editore, 2009.

DICIONÁRIO DA LÍNGUA PORTUGUESA. Lisboa: Priberam Informática. Disponível em: <http://www.priberam.pt/DLPO>. Acesso: 10 jun. 2019.

FO, Dario; RAME, Franca. Tutto il teatro de Dario Fo e Franca Rame: Tuttacasa, letto e chiesa. Milano: Fabri Editori, 2005.

NUNES MELO, Sérgio. In: SOUSA, Cristiana Almeida de. A mãe desbundada x La mamma fricchettona: As escolhas do tradutor Sérgio Nunes Melo para a tradução do monólogo de Dario Fo e Franca Rame. Trabalho de Conclusão de Curso - Universidade Federal da Bahia, Salvador, 2015. Disponível em <http://repositorio.ufba.br/ri/handle/ ri/25483>. Acesso em: 15 jun. 2019.

RAMOS, Graciliano. Vidas secas. São Paulo: Record, 2006.

SOUSA, Cristiana Almeida de. A mãe desbundada x La mamma fricchettona: As escoIhas do tradutor Sérgio Nunes Melo para a tradução do monólogo de Dario Fo e Franca Rame. Trabalho de Conclusão de Curso - Universidade Federal da Bahia, Salvador, 2015. Disponível em <http://repositorio.ufba.br/ri/handle/ri/25483>. Acesso em 15 de junho de 2019.

VENEZIANO, Neyde. A cena de Dario Fo: o exercício da imaginação. São Paulo: Códex, 2002. 
VENUTI, Lawrence. Escândalos da tradução: por uma ética da diferença. Tradução de Laureano Pelegrin, Lucinéia Marcelino Villela, Marileide Dias Esqueda e Valéria Biondo. Bauru, SP: EDUSC, 2002.

Recebido em: 19/06/2019

Aprovado em: 10/07/2019 